15

\title{
Исследование седиментации ферромагнитных наночастиц в магнитной жидкости методом ЯМР
}

\author{
(C) С.В. Дьяченко, И.С. Кондрашкова, А.И. Жерновой \\ Санкт-Петербургский государственный технологический институт (Технический университет), \\ 190013 Санкт-Петербург, Россия \\ e-mail: samyon2008@yandex.ru
}

(Поступило в Редакцию 22 февраля 2017 г.)

\begin{abstract}
Предложен способ исследования седиментации ферромагнитных наночастиц в магнитной жидкости по скорости уменьшения ее намагниченности, измеряемой методом ЯМР. Исследована зависимость скорости изменения намагниченности магнитной жидкости во времени от концентрации стабилизатора. В качестве магнитной жидкости использовался коллоидный раствор наночастиц магнетита в воде со стабилизатором олеатом натрия, концентрация которого варьировалась. Получено, что в стабильной магнитной жидкости отношение массовых концентраций стабилизатора и магнетита должно превышать условие $C \geq 0.7$, что соответствует образованию двойного слоя стабилизатора на поверхности наночастиц магнетита.
\end{abstract}

DOI: 10.21883/JTF.2017.10.45007.2213

\section{Введение}

Магнитная жидкость - это стабилизированный коллоидный раствор ферромагнитных наночастиц [1]. Со временем в таком растворе может протекать процесс уменьшения седиментационной устойчивости. Седиментационная устойчивость - это устойчивость системы против снижения потенциальной энергии частиц дисперсной фазы при их оседании под действием силы тяжести [2]. То есть седиментация - это процесс оседания частиц в растворе, приводящий к уменьшению их концентрации. Измерение скорости седиментации играет важную роль для оценки устойчивости коллоидных растворов. В настоящее время для этой цели применяются оптические методы [3], основанные на увеличении прозрачности раствора при уменьшении концентрации, однако они неприменимы для растворов малой прозрачности. Имеются также методы, основанные на взвешивании осевших частиц [2]. Эти методы трудно использовать для магнитной жидкости вследствие малой массы наночастиц.

Для измерения скорости седиментации ферромагнитных наночастиц можно использовать зависимость намагниченности $(M)$ магнитной жидкости от времени $(t)$, так как при оседании наночастиц средняя намагниченность раствора уменьшается. В стабильной магнитной жидкости седиментация отсутствует, поэтому намагниченность во времени практически не меняется. Чем не стабильнее магнитная жидкость, тем быстрее уменьшается ее намагниченность. Стабильность магнитной жидкости определяется концентрацией стабилизатора коллоидного раствора, в качестве которого применяются поверхностно-активные вещества (ПАВ), молекулы которых, осаждаясь на поверхности ферромагнитных наночастиц, препятствуют их коагуляции.

В работе [4] был проведен экспериментальный анализ влияния концентрации стабилизатора на устойчивость магнитной жидкости, который показал, что для водного раствора наночастиц магнетита, стабилизированного олеатом натрия, оптимальным является массовое соотношение $(C)$ олеата натрия $\left(m_{\mathrm{stab}}\right)$ и магнетита $\left(m_{\mathrm{magn}}\right)$ в растворе $\left(C=m_{\text {stab }} / m_{\text {magn }}\right)$ равно $C=0.7$. При других концентрациях стабилизатора коллоидный раствор становится нестабильным. А в работе [5] по оптимальному значению $C=0.7$ произведен расчет толщины слоя стабилизатора, который оказался равен $\approx 4-5 \mathrm{~nm}$, что соответствует длине двух молекул олеата натрия. На основании расчета высказана гипотеза, что для стабильности водных магнитных жидкостей оптимальной является такая концентрация стабилизатора, когда на поверхности каждой наночастицы образован двойной слой его молекул. В настоящей работе осуществлена проверка этого соотношения по экспериментальной зависимости намагниченности магнитной жидкости от времени при различной концентрации стабилизатора.

\section{Экспериментальная часть}

Для синтеза магнитной жидкости использовались: ферромагнитные частицы - синтетический магнетит, дисперсионная среда - вода, стабилизатор - олеат натрия. В качестве прекурсоров для получения частиц магнетита применялись: $\mathrm{FeCl}_{2} \cdot 4 \mathrm{H}_{2} \mathrm{O}$ (имп. PRS); $\mathrm{FeCl}_{3} \cdot 6 \mathrm{H}_{2} \mathrm{O}$ марки ч. (ГОСТ 4147-74); 25\%-ный раствор $\mathrm{NH}_{3} \cdot \mathrm{H}_{2} \mathrm{O}$ марка 23-5 осч. (ГОСТ 24147-80); дистиллированная вода (ГОСТ 6709-72). Олеат натрия был приготовлен из олеиновой кислоты $\left(\mathrm{C}_{17} \mathrm{H}_{33} \mathrm{COOH}\right.$ марки Б-115 тех. (ГОСТ 29039-91)) путем ее нейтрализации гидроксидом натрия ( $\mathrm{NaOH}$ марки х.ч. (имп.)) в среде этилового спирта с последующим испарением растворителя и термообработкой продукта в сушильном шкафу при температуре $40-50^{\circ} \mathrm{C}$ в течение 4 hours. Синтез магнитной жидкости осуществлялся по методу химической конденсации при начальной температуре 
раствора солей железа $25^{\circ} \mathrm{C}$. Подробная методика синтеза магнитной жидкости описана в [6].

Для исследования седиментации ферромагнитных наночастиц в магнитной жидкости проводилось измерение зависимости ее намагниченности $(M)$ от времени $(t)$. Намагниченность измерялась на экспериментальной установке, схема установки и принцип работы приведены в [7]. В этом способе методом ЯМР измерялись индукция $B$ и напряженность $H$ магнитного поля внутри образца магнитной жидкости, а намагниченность находилась по формуле $M=\left(B / \mu_{0}\right)-H$. Измерения проводились в течение $t=70 \mathrm{~min}$ (предварительно перед измерением намагниченности производилось взбалтывание образца магнитной жидкости в течение $40 \mathrm{~s}$ с целью приведения всех образцов в одинаковые начальные условия). По результатам эксперимента находилась зависимость $M(t)$ для образцов магнитной жидкости, по которой графически определялась скорость седиментации наночастиц для конкретной концентрации стабилизатора:

$$
v=d M / d t .
$$

Для проведения эксперимента было приготовлено 8 образцов магнитной жидкости. Каждый образец имел постоянную концентрацию магнетита $93 \mathrm{~kg} / \mathrm{m}^{3}$ и различную относительную концентрацию стабилизатора $(C)$ : $0.10,0.23,0.30,0.40,0.50,0.60,0.71,0.96$.

\section{Результаты}

На рис. 1 приведена зависимость $M(t)$ для 4 из 8 образцов магнитной жидкости с различной концентрацией стабилизатора $C$. Из рис. 1 следует, что в начальный момент времени $\left(t_{0}\right)$ для различных магнитных жидкостей величина начальной намагниченности $\left(M_{0}\right)$ различна, это связано с образованием разного соотношения количеств магнитной и немагнитной составляющих в наночастицах магнетита при их синтезе при $25^{\circ} \mathrm{C}$. Уменьшение величины намагниченности со временем можно объяснить уменьшением средней концентрации ферромагнитных наночастиц в растворе. С течением

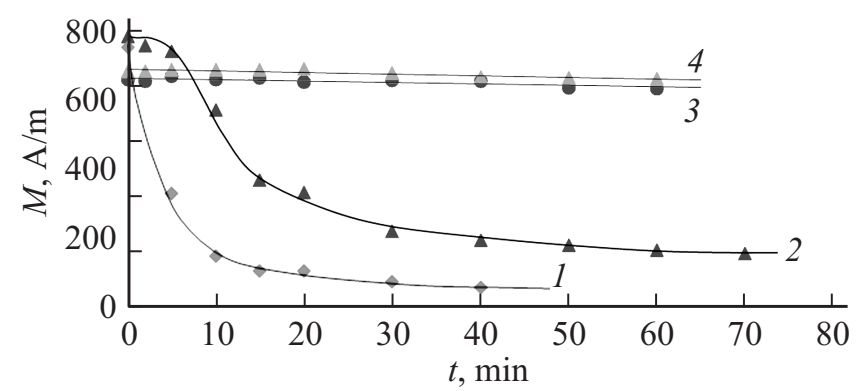

Рис. 1. Зависимость намагниченности магнитной жидкости $(M)$ с различной концентрацией стабилизатора $(C)$ от времени $(t)$ в постоянном магнитном поле с напряженностью $6800 \mathrm{~A} / \mathrm{m}$. Кривая $1-C=0.40$, кривая $2-0.60$, кривая $3-$ 0.71 , кривая $4-0.96$.

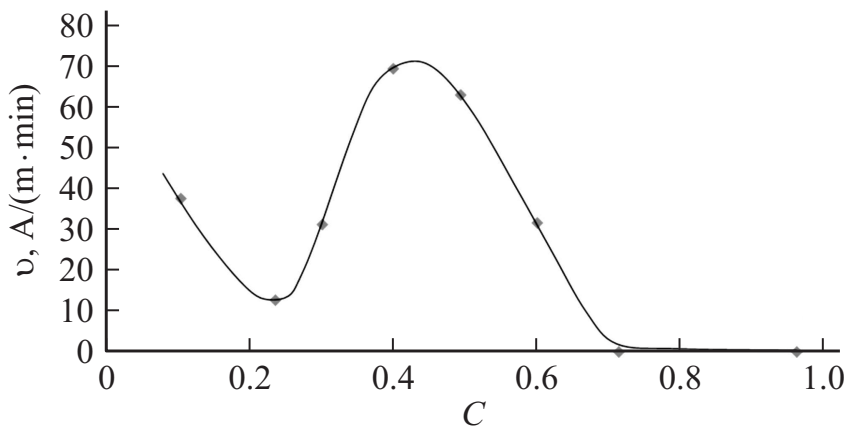

Рис. 2. Зависимость скорости седиментации от концентрации стабилизатора в магнитной жидкости. Концентрация выражена как отношение масс стабилизатора и ферромагнитных наночастиц.

времени значение $M$ уменьшается от $M_{0}$ до некоторого значения $M_{1}$, при котором большая часть наночастиц перешла в осадок. При этом значении седиментация ферромагнитных наночастиц преимущественно закончена. Из графиков, приведенных на рис. 1, можно определить скорость седиментации наночастиц $(v)$ в различные моменты времени $t$. Построим зависимость скорости седиментации от концентрации $(C)$ стабилизатора (рис. 2).

Из рис. 2 следует, что на промежутке изменения $C$ от 0 до 0.23 значение $v$ падает, на промежутке изменения $C$ от 0.23 до 0.40 значение $v$ возрастает, а на промежутке изменения $C$ от 0.40 до 0.71 значение $v$ снова падает, достигая минимума при значении 0.71, оставаясь постоянным до значения 0.96. Исходя из этого, можно заключить, что при концентрации стабилизатора в растворе $C \geq 0.71$ магнитная жидкость становится стабильной. При значении $C=0.23$ имеется минимум, который можно отнести к условию создания псевдостабильной жидкости, а при $C=0.40$ максимум, который можно отнести к неравновесному состоянию раствора, так как в этой точке скорость седиментации максимальна.

Полученный экспериментальный результат можно сопоставить с теоретическими расчетами концентрации стабилизатора в растворе, а соответственно и с толщиной слоя стабилизатора на наночастицах магнетита. Известно, что длина молекулы олеата натрия составляет примерно $2 \mathrm{~nm}$ [5]. Представив наночастицу магнетита в виде шара с диаметром $14 \mathrm{~nm}$ (по данным из РФА [6]) и зная массу полученного в ходе реакции магнетита $m_{\text {magn }}=4.6614 \cdot 10^{-3} \mathrm{~kg}$, можно рассчитать массу добавляемого олеата натрия в раствор наночастиц магнетита, чтобы на поверхности наночастиц создать один слой стабилизатора толщиной $2 \mathrm{~nm}$, при условии, что весь добавляемый олеат будет адсорбироватся на поверхности наночастиц. Масса добавки стабилизатора составит $m_{\text {stab }}=1.1 \cdot 10^{-3} \mathrm{~kg}$, а относительная концентрация $C=0.23$. Для получения двойного слоя толщиной $4 \mathrm{~nm}$ необходимо добавить $m_{\mathrm{stab}}=2.8 \cdot 10^{-3} \mathrm{~kg}$, что соответствует $C=0.60$. 
Сопоставив экспериментально полученную зависимость на рис. 2 и теоретические расчеты, можно сделать вывод, что для получения стабильной магнитной жидкости необходим ввод большего количества стабилизатора, чем требуется из расчета. Разница для получения двойного слоя стабилизатора в $4 \mathrm{~nm}$ из теоретического расчета $C=0.60$, а из практики $C=0.71$ составляет $\approx 16 \%$ (в эксперименте этот результат подтверждается нулевой скоростью седиментации).

Также, исходя из расчетов при значении $C=0.23$, должны создаваться условия для покрытия наночастиц магнетита одним слоем стабилизатора, в связи с чем должна уменьшаться скорость седиментации. На практике при значении $C=0.23$ скорость седиментации действительно уменьшается, но жидкость не становится стабильной. По-видимому, препятствие для оседания создает либо один слой стабилизатора на всех наночастицах, который недостаточен для получения стабильной жидкости, либо покрытие только части частиц более чем одним слоем. Это состояние можно охарактеризовать как неустойчивое равновесие. Далее до значения $C=0.40$ происходит увеличение скорости седиментации, это связано с продолжением адсорбции олеата натрия на покрытые одним слоем стабилизатора наночастицы. Это приводит к последующему связыванию через „мостик“ стабилизатора наночастиц, покрытых одним слоем, и наночастиц без стабилизатора, что вызывает оседание наночастиц и их конгломератов. При значении $C \geq 0.40$ скорость седиментации вновь уменьшается вследствие достижения такой концентрации стабилизатора в растворе, при которой создаются благоприятные условия для образования на поверхности всех наночастиц в магнитной жидкости двойного слоя стабилизатора. При повышении концентрации адсорбция увеличивается, и уже поверхность наночастиц насыщается стабилизатором, полностью покрывающим все наночастицы двойным слоем при $C \approx 0.70$. Магнитная жидкость при этом становится стабильной. Стоит отметить, что повышение концентрации олеата натрия вызывает увеличение вязкости раствора, которое также препятствует оседанию.

\section{Заключение}

Предложенный способ исследования процесса седиментации ферромагнитных наночастиц методом ЯМР дает возможность экспериментальной экспресс-оценки стабильности магнитных жидкостей, которая важна при применении, например в медицине [8]. Поэтому он может использоваться в качестве метода для контроля магнитных жидкостей на предприятиях по их изготовлению.

Адекватность предложенного метода подтверждается соответствием экспериментально полученных условий создания стабильной магнитной жидкости в настоящей работе и результатов, полученных в других работах $[4,5]$. Таким образом, можно заключить, что предложенный метод может применяться для определения механизма стабилизации, количества вводимого стабилизатора и подбора его оптимальной концентрации в коллоидных растворах.

\section{Список литературы}

[1] Полунин В.М. Акустические свойства нанодисперсных магнитных жидкостей. М.: Физматлит, 2011. 425 с.

[2] Щукин Е.Д., Перцов А.В., Амелина Е.А. Коллоидная химия. М.: Высш. шк., 2004. 445 с.

[3] Веролайнен Н.В. и др. // Вестник ТвГУ. Сер. Химия. 2012. Вып. 13. С. 89-98.

[4] Матусевич Н.П. // Проблемы механики магнитных жидкостей. Минск: ИТМО АН БССР, 1981. С. 3-10.

[5] Берковский Б.М., Медведев В.Ф., Краков М.С. Магнитные жидкости. М.: Химия, 1989. 289 с.

[6] Дьяченко С.В. и др. // ЖПХ. 2016. Т. 89. Вып. 5. С. 113-119.

[7] Жерновой А.И., Дьяченко С.В. // ЖТФ. 2015. Т. 85. Вып. 4. С. $118-122$.

[8] Постнов В.Н. и др. // Биотехносфера. 2013. № 6(30). C. $16-27$. 